\title{
MEASURING INPUT PRODUCTIVITY GAINS FROM INFORMATION TECHNOLOGY
}

\author{
by \\ Rajiv D. Banker \\ School of Urban and Public Affairs \\ Carnegie Mellon University \\ Pittsburgh, PA 15213 \\ $412-26 S-2171$ \\ Robert J. Kauffman \\ Leonard N. Stern School of Business \\ New York University \\ 90 Trinity Place \\ New York, NY 10006 \\ 212-2\$5-6079 \\ and \\ Richard C. Morey \\ School of Buisness \\ University of Cincinati \\ Cincinati, OH 45221 \\ 513-556-7140
}

January 1989

Center for Research on Information Sirstems

Information Systems Department

Leonard N. Stern School of Business

New York University

\section{Working Paper Series}

CRIS \#196

GBA \#S9-S

Submitted to SIGOIS Workshop on the Impact and Value of Information Systems. 


Abstract
This paper proposes a new method to measure the input productivity gains from information technology in
complex managerial environments. The method employs a production function which maps output and
relating moderating variables in the managerial environment into input resource consumption, with a
random inefficiency component which can be affected by IT deployment. Sample hypotheses and a sketch
of the F-tests used to identify reductions in input inefficiency are presented, and then illustrated for a new
information technology which has recently been deployed in fast food restaurants.




\section{Introduction}

Today, senior managers are faced with making decisions about how to spend historically large information technology (IT) budgets without the comfort and guidance of systems of performance measurement that are broadly accepted in practice and well-grounded in theory. As a result, there is much confusion about how measurement of the business value impacts of IT actually should be carried out. For example, the results of the American Banker's "1988 Managing Technology Survey" [22] showed that 55\% of 188 senior executives in bank operations believed that the return on their investments in IT are either good or excellent, though one-half of them do not have any formal systems in place to measure ROI. Similar results were also found in an Index Group survey of 240 senior information systems managers for a broader cross-section of industries. Computerworld reported that only one in ten executives polled indicated that they knew how to adequately evaluate the business value of their IT investments. ${ }^{1}$

Although investments in information technology made by large corporations can result in a variety of strategic impacts, the kinds which most senior managers probably feel they have the best understanding of are those that lead to relatively direct operating cost savings. (In fact, this could well account for why so many senior managers are not putting much effort toward measurement.) But, for many large and wellmanaged companies, the days of easy payoffs from automating operations are long gone. Instead, as the decade of the 1980s draws to a close, many observers would agree that major corporate investments in IT that will lead to operating cost reductions are made with the goal of "fine-tuning" the effects of previous IT investments on production.

\section{Rethinking Efficiency Measurement for IT}

\subsection{Previous Research on IT Impact Analysis}

Recent research on IT performance evaluation has emphasized the need to investigate intermediate production as a means to understand how IT leads to the creation of business value (for example, see Benham [8], Crowston and Treacy [11], Banker and Kauffman [4, 5], Kauffman and Kriebel [14, 15], Parker and Benson [17], and Zajonc [21]). This reflects a recognition among researchers that it is methodologically quite difficult to develop robust measures linking IT investments to bottom line impacts, without taking some pains to capture how the "conversion" from investment to value occurs, and whether it is effective [20].

Earlier studies by Jonscher [13], Stabell [19], Chismar and Kriebel [10], and more recent work by Harris and Katz [12] and Loveman [16] have taken a different approach, concentrating on strategic business unit and firm level aggregate analysis. At this level, however, IT has been shown to provide few concrete

${ }^{1}$ Computerworld, November 8, 1988, p.8 
payoffs to justify the great expenditures, yet managers continue to invest. As we begin the 1990s, the art of IT investment is still far ahead of the science of evaluation.

\subsection{Measures for Competitive and Operational Efficiency}

Although we support the argument that the science of measuring the effectiveness of IT investments will improve through the application of process models, we believe that additional consideration should be given to the theory base which provides guidance for how IT influences efficiency. In our current program of research on measuring IT-related efficiency gains, we distinguish between competitive efficiency and operational efficiency for IT.

Competitive efficiency measures describe the relationship between technology investments and other major firm level expenditures, and bottom line impacts, such as revenues, profitability and return on assets, among others. Thus, firms which exhibit a high level of competitive efficiency tend to do better than other firms which deploy similar levels of resources. Based on our definition, the second group of studies mentioned above can be broadly classified as competitive efficiency analyses of IT investment. Clearly, IT plays an important role in helping some of these firms to secure better performance than their competitors, but competitive efficiency measures alone do little to explain how some firms benefit, and to what extent. Such aggregate measures are "out of sync" with the real measurement problem. Potential users of the results and the methods of the studies need to bear in mind that they are meant to be descriptive, rather than normative.

Operational efficiency measures describe IT performance in intermediate production processes. They provide a means to gauge whether conversion of IT investments into business value is occurring in the "micro" production environments most affected by IT. This is where management efforts to "fine-tune" operations are centered, so it makes sense that IT performance measures should either directly relate to, or be derived from, the operations the IT supports.

\subsection{IT's Impact on Random Inefficiency in Complex Managerial Environments}

The remainder of the paper focuses on the exposition of a new method for the measurement of IT-related gains in input efficiency in complex production settings. By complex production settings, we refer to situations in which IT is just one among a number of factors in the managerial environment which can affect the consumption of resources in the production of physical or service outputs. Although IT may affect the outcome, it will be difficult to separate out its contribution from those of other factors present in the managerial environment. When IT is used to support production, its value is often derived from how it can improve the likelihood that cost-minimizing production decisions are made by managers. Value will also be created, if, on average, IT helps to reduce inventory, cut material waste, or control labor overtime.

To address these concerns, we propose a new method based on Data Envelopment Analysis (DEA) (for 
example, see Banker [2], and Banker, Charnes and Cooper [1]). Banker and Morey [6] have suggested utilizing hypothesis tests to identify "separation" in the performance frontiers of business units which operate under materially different conditions. In addition, Banker [ 7 ] has proposed the use of an F-statistic test, which enables hypothesis testing utilizing non-parametric production frontiers. This method:

- addresses the problem of IT's role in complex production environments by modelling the production process, rather than focusing on the IT;

- incorporates a random variable, $\theta$, to represent the level of inefficiency that IT can affect, in a generalized production function;

- employs hypothesis testing to determine if micro-production performance in the presence and absence of an IT differs;

- opens up the possibility of creating an IT performance audit baseline, which can be used for comparison purposes in later periods, or to pinpoint the timing of the impact.

\section{A Model Which Captures IT Effects on Input Inefficiency}

As a basis for our illustration of these ideas, we will work with a simplified production function which highlights the probabilistic manner in which IT affects input productivity. We define a production function which maps output and a set of variables in the managerial environment which moderate output, into input consumption. This relation, which includes a random inefficiency component, is written as follows:

$$
c=f(Y, Z) * \theta
$$

where

c = the actual consumption of the input resource

$\mathrm{Y} \quad=\mathrm{a}$ vector of the outputs of the production process

$\mathrm{Z} \quad=\mathrm{a}$ vector of explanatory variables for consumption variances

$\theta \quad=a$ random variable for inefficiency, whose values range between 1 and infinity, for example, in an exponential distribution with $E[\theta]=1+(1 / \lambda)$ and the probability density function, $g(\bullet)$, given by: ${ }^{2}$

$$
g(\theta \mid \lambda)=\lambda e^{-\lambda(\theta-1)} \text {, for } \theta>=1 \text {, and } 0 \text { otherwise }
$$

We further assume that the production function, $\mathrm{f}(\bullet)$, is monotone, increasing, and convex. These assumptions place minimal structure on the form of the function, and enable the application of our method to a wide range of production environments influenced by IT. By including the random variable for inefficiency, $\theta$, the method also directly answers concerns which have been raised about the utilization of

\footnotetext{
${ }^{2}$ Since inefficiency scores vary between 1 and infinity, we adjust the mean of the standard exponential distribution $(1 / \lambda)$ when the random variable varies between 0 and infinity, by adding one to it.
} 
non-parametric production frontiers in the econometrics literature (for example, see Schmidt [18]) in situations where hypothesis testing is necessary. If a deterministic inefficiency variable were used instead, there would be no means to distinguish between inefficiency and measurement error.

\section{An Illustration: IT Deployment in Fast Food Restaurants}

\subsection{Setting and Data}

We intend to illustrate this approach with actual data we have obtained from Hardee's, a large fast food retailer based in Rocky Mount, North Carolina. Hardee's has deployed a relatively new information technology called a "Positran" in many of its restaurants. It attaches to a cash register and displays the order on a CRT screen, as it is entered into the cash register. This equipment also transmits the order to the food preparation area, and its use is intended to increase the likelihood that an order is correctly recorded, thus reducing input material waste caused by the non-matching of the delivery with the order. Comparing restaurant operations where Positran has been deployed and where it has not provides a natural testbed for identifying whether there is some component of the random inefficiency variable, $\theta$, that systematically varies with the deployment of Positran. Among the 91 restaurants whose operations we will evaluate, 42 restaurants had implemented Positran at least one month prior to the study period, while 49 did not.

The output vector, $Y$, consists of $y_{\text {BRK_SALES }}$, the dollar level of breakfast sales, and $y_{\text {OTHER_SALES }}$, lunch and dinner sales. Input consumption consumption, $c$, represents aggregate materials cost. All data collected reflect observations for individual restaurants for a representative quarter of the same year. The vector of environmental factors, $Z$, is comprised of two categorical variables, representing those aspects of the production environment which management believes to have the most direct influence on input resource consumption. Based on performance studies conducted by management in the past, we include a dummy, $z_{\text {WINDOw, }}$ to indicate whether a restaurant has a drive-through window. The presence of a drivethrough window tends to complicate order control and production, and has been shown to result in higher materials consumption. Deployment of the Positran technology is included in the production function using a second dummy, $z_{\mathrm{rT}}$. Based on the description we gave earlier, Hardees restaurants would qualify as a complex production environment.

Rewriting the generalized cost function for this application, we have the following:

$$
\mathrm{c}=\mathrm{f}\left(\mathrm{y}_{\text {BRK_SALES }}, \mathrm{y}_{\text {OTHER_SALES }}, \mathrm{z}_{\text {WLNDOW }}, \mathrm{z}_{\mathrm{IT}}\right) * \theta
$$

Restaurants can be distinguished by other variables such as the quarterly volume of restaurant sales, square feet of restaurant floor space, and number of cashier positions. We will discuss some of these further below. 


\subsection{Constructing Basic Hypothesis Tests}

For the purpose of testing the hypothesis that the presence of Positran equipment improves input productivity, let $j$ represent a restaurant in the overall data set. The set $J$ of restaurants consists of two subsets, $A_{1}$ and $A_{2}$. Restaurant $j$ is an element of the subset $A_{1}$ if management has not installed Positran on its premises, and an element of $\mathrm{A}_{2}$ if Positran has been installed. We will denote the the inefficiency of the observations in group $A_{i}$ by $\theta_{i}$ to distinguish them, and allow for the possibility that the probability distribution of $\theta_{1}$ differs from that of $\theta_{2}$. Let the distribution of $\theta_{1}$ be exponential with mean $1+\left(1 / \lambda_{1}\right)$, and $\theta_{2}$ be exponential with $1+\left(1 / \lambda_{2}\right)$. Thus, the simplest null hypothesis is:

$$
\mathrm{H}_{0}: \lambda_{1}=\lambda_{2}
$$

Of course, the alternate hypothesis here is:

$$
\mathrm{H}_{1}: \lambda_{1}>\lambda_{2}
$$

i.e., that IT deployment leads to a reduction in input inefficiency on average.

This kind of hypothesis test is of general interest whenever management wishes to determine whether the differential efficiency of two groups of business units can be attributed in some way to endogenous or exogenous aspects of the environment in which managerial decisions are carried out. Charnes, Cooper and Rhodes [9], for example, compared school performance with and without the presence of an accountability program. Banker, Datar and Kemerer [3], using software development projects as their unit of analysis, attempted to correlate code development labor productivity with the use of a structured development methodology.

We can enrich our analysis by testing to determine if the parameter for the mean of the distribution of efficiency scores differs across groups of restaurants with common features. With a relatively large data set, it can be partitioned into groups of restaurants based on the characteristic which is believed to cause the distribution of efficiency scores to shift. Table 1 below shows four partitions of the data based on the presence and absence of Positron, and restaurant size in terms of dollar volume of sales. We also include the notation we use below to distinguish the means of the $\theta$ distributions.

Two revised null hypothesis tests related to the means of the distributions describing the data partitions are of interest:

$$
\mathrm{H}_{0}^{\prime}: \lambda_{11}=\lambda_{12}
$$

and

$$
\mathrm{H}^{\prime \prime}: \lambda_{21}=\lambda_{22}
$$

The purpose of hypothesis $\mathrm{H}_{0}{ }_{0}\left(\mathrm{H}^{\prime \prime}{ }_{0}\right)$ is to determine whether large (small) restaurants without Positran exhibit input inefficiencies which are distributed similar to those for large (small) restaurants with Positran. 
Table 1: Hypothesized Means for Four $\theta$-Distributions

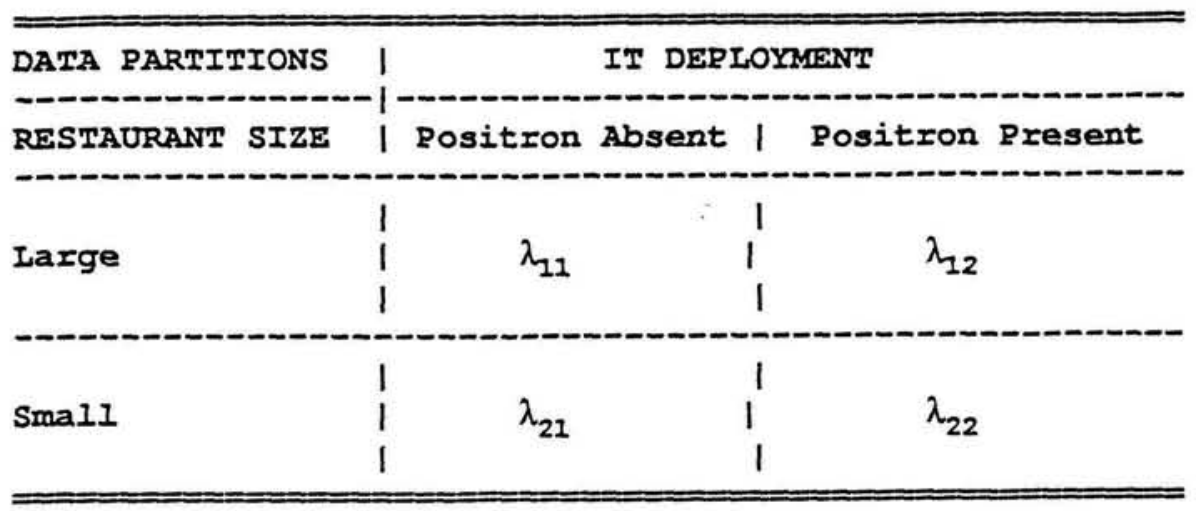

We expect that $H_{0}{ }_{0}$ will not be rejected because restaurants with larger sales volumes usually have a person assigned full time to act as a workflow coordinator between the cashier stations and the food preparation area. As a resuit, IT deployment in large restaurants may not have much impact because its monitoring activities are duplicated by the workflow coordinator. On the other hand, we expect that $H^{\prime \prime}{ }_{0}$ will be rejected, indicating that the IT has a significant impact in reducing inefficiencies in only small restaurants. The smaller sales volume in these restaurants makes it more difficult to justify having a workflow coordinator, so the likelihood of wasting inputs due to poor coordination between the cashiers and the food preparers would likely increase, but only in the absence of the IT.

This general approach can also be used to examine the extent to which the physical size, number of cashier positions and presence of a drive-up window in a restaurant affect input inefficiency. Clearly, management will want to use as much information as it has available to enhance the usefuiness of the results for managers. Next, we turn to a discussion of the details of the test statistics used to carry out these hypothesis tests.

\subsection{Carrying Out the Hypothesis Tests}

Generally speaking, the probability of a small amount of input consumption inefficiency in production is very high, while the probability of highly inefficient operations is very low (If management is "fine-tuning" operations by utilizing IT, it is likely that gross inefficiencies will have been dealt with previously.) An exponential distribution for the inefficiency scores, $\theta$, is appropriate when the analyst believes most of the observations are very close to the efficient frontier. If fewer observations are expected to be very near to the frontier, then it is appropriate to use a half-normal distribution to represent $\theta$ 's probability distribution. Both distributions capture the idea that the likelihood of inefficient observations decreases very rapidly as $\theta$ gets larger. 
After solving an appropriate DEA model to determine the set of efficiency scores, hypothesis tests then can be carried out to determine whether the means of the probability distributions are actually different. The relevant test statistic has been suggested by Banker [7]. We assume a large sample of DEA inefficiency scores, $\theta_{\mathrm{j}}$. With

$$
\sum_{j \varepsilon A_{1}} 2 \theta_{j} / \lambda_{1}
$$

and

$$
\sum_{j \notin A_{2}} 2 \theta_{j} / \lambda_{2}
$$

asymptotically distributed as chi-squares with $2 a_{i}$ degrees of freedom, where $a_{i}, i=1,2$ is the number of observations in the sets $A_{1}$ and $A_{2}$, it follows that under the null hypothesis the statistic

$$
\sum_{j \notin A_{1}} \theta_{j} / \sum_{j \gtrless A_{2}} \theta_{j}
$$

is asymptotically distributed as an F-distribution with $2 \mathrm{a}_{1}, 2 \mathrm{a}_{2}$ degrees of freedom.

For example, to test the revised null hypothesis, $\mathrm{H}_{0}^{\prime}: \lambda_{11}=\lambda_{12}$, which was constructed to determine whether Positran has a beneficial effect on input consumption in large restaurants, we utilize a similar ratio of the sums of the inefficiency scores, adjusted to reflect the interval, $[1, \infty)$, over which they actually vary. The adjusted test statistic is

$$
\sum_{j \in A_{11}}\left(\theta_{j}-1\right) / \sum_{j \in A_{12}}\left(\theta_{j}-1\right)
$$

again an F-distribution with $2 a_{11}, 2 a_{12}$ degrees of freedom.

When it is more appropriate to assume that $\theta$ follows a half-normal distribution with parameter $\sigma$, then the test statistic can be revised to reflect that the sum

$$
\sum_{j \in A_{i}}((\theta-1) / \sigma)^{2}
$$

is distributed as a chi-square with $\mathrm{a}_{\mathrm{i}}$ degrees of freedom. ${ }^{3}$ Here we would test the revised null hypothesis, $\mathrm{H}_{0}^{\prime}: \sigma_{11}=\sigma_{12}$, rewritten to include the parameter of the half-normal distribution. Under the null hypothesis, the revised ratio includes the squares of the inefficiency scores as follows:

$$
\sum_{j \varepsilon A_{11}}\left(\theta_{j}-1\right)^{2} / \sum_{j \varepsilon A_{12}}\left(\theta_{j}-1\right)^{2}
$$

This also follows an F-distribution.

\footnotetext{
${ }^{3}$ When the appropriate distribution for $\theta$ is not clear, it is also possible to carry out the analysis. Banker [7] suggested the use of Kolmogorov-Smimov non-parametric tests to identify whether the distribution of $\theta_{11}$ or $\theta_{12}$ stochastically dominates the other.
} 


\section{Conclusion}

While IT's role in helping American business to improve its competitiveness by reducing the costs of production is unquestioned, senior managers responsible for large IT budgets have expressed concern about just how well their investments are performing. In this paper, we have argued that it is becoming increasingly important to measure IT impacts in the actual production contexts in which they occur. It is also important to point out that the use of IT for "fine-tuning" operations places added emphasis on methods which realistically recognize the variety of factors which can produce results similar to those which derive from the deployment of IT, e.g., productivity incentive programs, management training, upgraded physical facilities, and so on. Compounding the problem of IT performance assessment is the reality that identical ITs may be utilized in rather different ways in different units of a firm.

Using a new IT deployed at Hardees fast food restaurants as an illustrative example, we have shown how to model the way in which IT enters the production process, and can potentially affect input productivity. We also have shown how to detect such probabilistic impacts of IT by testing hypotheses which enable the identification of the differences in the distributions of inefficiencies for restaurants with and without the IT. Finally, a more elaborate test is also illustrated to identify whether the effectiveness of IT varies with its deployment at large versus small restaurants.

The contributions of this work to the literature on IT impact analysis are:

- the recognition that IT has a probabilistic impact on operational efficiency;

- the method suggested to operationalize the analysis.

Our approach utilizes strong methods based on production economics and mathematical programming, yet can be conducted by managers who have access to desktop workstations. We expect that its use will help managers to gain a deeper understanding of the critical environmental factors that to lead differential return on IT investments in complex managerial environments. 


\section{References}

[1] Banker, R. D., and A. Charnes and W. W. Cooper.

Some Models for Estimating Technical and Scale Inefficiencies in Data Envelopment Analyis. Management Science 30(9):1078-1092, September, 1984.

[2] Banker, R. D.

Productivity Measurement and Management Control.

The Management of Productivity and Technology in Manufacturing.

Plenum Publishing, New York, 1985.

[3] Banker, R. D., S. M. Datar and C. F. Kemerer.

Software Development Productivity Measurement.

In Proceedings of the Eighth International Conference on Information Systems. Pittsburgh, Pennsylvania, December, 1987.

[4] Banker, R. D., and R. J. Kauffman.

Strategic Contributions of Information Technology: An Empirical Study of ATM Networks.

In Proceedings of the Ninth International Conference on Information Systems. Minneapolis, Minnesota, December, 1988.

[5] Banker, R. D., and R. J. Kauffman.

Quantifying the Business Value of Information Technology.

May, 1988.

Working paper, Graduate School of Industrial Administration, Camegie Mellon University.

[6] Banker, R. D., and R. C. Morey.

Evaluating Hypotheses in Efficiency Analysis: An Application.

July, 1988.

Working Paper, School of Urban and Public Affairs, Carnegie Mellon University.

[7] Banker, R. D.

Maximum Likelihood, Consistency and Data Envelopment Analysis: A Statistical Foundation.

July, 1988.

Working Paper, School of Urban and Public Affairs, Carnegie Mellon University.

[8] Benham, H. C.

A Measure of Information System Impact.

October, 1988.

Working Paper, Division of Economics, University of Oklahoma.

[9] Charnes, A., W. W. Cooper and E. Rhodes.

Measuring the Efficiency of Decision Making Units.

European Journal of Operations Research 2(6), 1978.

[10] Chismar, W. C., and C. H. Kriebel.

A Method for Assessing the Economic Impact of Information Systems Technology on Organizations.

In Proceedings of the Sixth International Conference on Information Systems. Indianapolis, Indiana, December, 1985.

[11] Crowston, K., and M. E. Treacy.

Assessing the Impact of Information Technology on Enterprise Level Performance.

In Proceedings of the Seventh International Conference on Information System, pages 299-310.

San Diego, CA, December, 1986. 
[12] Harris, S. E. and J. L. Katz.

Profitability and Information Technology Capital Intensity in the Insurance Industry.

In Proceedings of the Twenty-First Annual Hawaii International Conference on System Sciences, pages 124-130. January, 1988.

[13] Jonscher, C.

Information Resources and Economic Productivity.

Information Economics and Policy 1: 13-35, 1983.

[14] Kauffman, R.J., and C. H. Kriebel.

Modeling and Measuring the Business Value of Information Technology.

Measuring the Business Value of Information Technologies.

ICIT Press, Washington, D.C., 1988.

Edited by ICIT Research Study Team \#2.

[15] Kauffman, R. J., and C. H. Kriebel.

Identifying Business Value Linkages for Production Processes Involving Information Technology. Advances in Working Capital Management.

JAI Press, New Haven, CT, 1989.

Forthcoming.

[16] Loveman, G.

An Assessment of the Productivity Impact of Information Technologies.

1988.

Working paper, Management in the 1990s, Sloan School, MIT.

[17] Parker, M. J., and R. J. Benson.

Information Economics: Linking Business Performance to Information Technology.

Prentice Hall, Englewood Cliffs, NJ, 1988.

[18] Schmidt, P.

Frontier Production Functions.

Econometric Reviews, 1985.

[19] Stabell, C. B., and F. Forsund.

Productivity Effects of Computers in Administration: An Exploratory Empirical Investigation.

1983.

Working Paper, Norwegian School of Economics and Business Administration.

[20] Weill, P.

The Relationship Between Investment in Information Technology and Firm Performance in the Manufacturing Sector.

PhD thesis, Stern School of Business, New York University, 1988.

[21] Zajonc, P. C.

Making the Case for Point-of Sale Debit at Gasoline Service Stations: An Exploratory Application of Business Value Linkage Impact Analysis.

December, 1988.

Working Paper, Stern School of Business, New York University.

[22] Zimmerman, W., ed.

American Banker 1988 Managing Technology Survey: The Impact on the Bottom Line.

International Thonpson Publishing Corp., New York, NY, 1988. 